Check for updates

Cite this: Phys. Chem. Chem. Phys., 2019, 21, 26483

Received 18th June 2019 Accepted 7th November 2019

DOI: 10.1039/c9cp03449h

rsc.li/pccp

\title{
Sulfur adsorption on coinage metal(100) surfaces: propensity for metal-sulfur complex formation relative to (111) surfaces
}

\author{
Da-Jiang Liu, (D) *a Peter M. Spurgeon, (D) ${ }^{b}$ Jiyoung Lee, $^{\text {ab }}$ Theresa L. Windus, $^{\text {ab }}$ \\ Patricia A. Thiel (iD abc and James W. Evans (iD ad
}

\begin{abstract}
Experimental data from low-temperature Scanning Tunneling Microscopy (LTSTM) studies on coinage metal surfaces with very low coverages of $S$ is providing new insights into metal-S interactions. A previous LTSTM study for $\mathrm{Cu}(100)$, and a new analysis reported here for $\mathrm{Ag}(100)$, both indicate no metal-sulfur complex formation, but an $\mathrm{Au}_{4} \mathrm{~S}_{5}$ complex was observed previously on $\mathrm{Au}(100)$. In marked contrast, various complexes have been proposed and/or observed on $\mathrm{Ag}(111)$ and $\mathrm{Cu}(111)$, but not on $\mathrm{Au}(111)$. Also, exposure to trace amounts of $\mathrm{S}$ appears to enhance mass transport far more dramatically on (111) than on (100) surfaces for $\mathrm{Cu}$ and $\mathrm{Ag}$, a feature tied to the propensity for complex formation. Motivated by these observations, we present a comprehensive assessment at the level of DFT to assess the existence and stability of complexes on (100) surfaces, and compare results with previous analyses for (111) surfaces. Consistent with experiment, our DFT analysis finds no stable complexes on $\mathrm{Ag}(100)$ and $\mathrm{Cu}(100)$, but several exist for Au(100). In addition, we systematically relate stability for adsorbed and gas-phase species within the framework of Hess's law. We thereby provide key insight into the various energetic contributions to stability which in turn elucidates the difference in behavior between (100) and (111) surfaces.
\end{abstract}

\section{Introduction}

There has been sustained interest in additive-enhanced surface mass transport on metal (M) surfaces exposed to chalcogens, especially sulfur (S) and oxygen $(\mathrm{O}) .{ }^{1-3}$ This relates to the broader emerging theme that metal surfaces can be dynamic or fluxional in nature (rather than static or frozen) under operating conditions during catalysis. ${ }^{4,5}$ With regard to additiveenhanced transport on coinage metals, previous studies revealed a contrasting dramatic enhancement for $\mathrm{Ag}(111)^{6}$ versus limited enhancement for $\mathrm{Ag}(100)^{7}$ upon exposure to S. A similar dramatic enhancement was also observed for $\mathrm{Cu}(111){ }^{2}$ While no experiments are currently available for $\mathrm{Cu}(100)$, we expect limited enhancement as for $\mathrm{Ag}(100)$.

There has long been speculation that metal mass transport across surfaces can be facilitated by the presence of readilyformed metal-additive complexes. ${ }^{1,8,9}$ An early example was the suggestion that the reported degradation of supported $\mathrm{Pt}$

\footnotetext{
${ }^{a}$ Ames Laboratory - USDOE, Iowa State University, Ames, Iowa 50011, USA. E-mail: dajiang@ameslab.gov

${ }^{b}$ Department of Chemistry, Iowa State University, Ames, Iowa 50011, USA

${ }^{c}$ Department of Materials Science \& Engineering, Iowa State University, Ames, Iowa 50011, USA

${ }^{d}$ Department of Physics and Astronomy, Iowa State University, Ames, Iowa 50011, USA
}

catalyst nanoparticles was due at least in part to formation of $\mathrm{PtO}_{2}$ which can efficiently transport Pt either across the surface or through the gas phase. ${ }^{1,10,11}$ Historically, this idea was only speculative as such complexes were not directly observed. However, low-temperature Scanning Tunneling Microscopy (LTSTM) with liquid He cooling offers the possibility to freeze the diffusive motion of any such complexes and thereby directly image them confirming (or disproving) their existence. When applied to $\mathrm{Cu}$ surfaces exposed to minuscule amounts of $\mathrm{S}$, LTSTM reveals $\mathrm{Cu}_{2} \mathrm{~S}_{3}$ "hearts" on $\mathrm{Cu}(111)$ and concatenations of these especially near steps, ${ }^{12,13}$ but no complexes and only isolated S adatoms on $\mathrm{Cu}(100) .{ }^{14}$ LTSTM applied to Ag surfaces exposed to minuscule amounts of $S$ reveals larger complexes on $\mathrm{Ag}(111)$ including $\mathrm{Ag}_{16} \mathrm{~S}_{13},{ }^{15}$ and in this paper we present new data demonstrating the lack of complexes on $\mathrm{Ag}(100)$. In contrast to $\mathrm{Cu}$ and $\mathrm{Ag}$, for $\mathrm{Au}$ surfaces exposed to $\mathrm{S}$, no complexes were observed by LTSTM on $\mathrm{Au}(111),{ }^{16}$ but an $\mathrm{Au}_{4} \mathrm{~S}_{5}$ complex and fragments of this complex were found on $\mathrm{Au}(100){ }^{17}$

Motivated by dramatic enhancement of mass transport for $\mathrm{Cu}(111)$ and $\mathrm{Ag}(111)$ exposed to trace amounts of $\mathrm{S},{ }^{2,6}$ previously Density Functional Theory (DFT) analyses was undertaken to assess stability of various $\mathrm{M}-\mathrm{S}$ complexes on $\mathrm{M}$ (111) surfaces for $\mathrm{M}=\mathrm{Cu}$ and $\mathrm{Ag}$. The first such DFT study considered $\mathrm{Cu}_{3} \mathrm{~S}_{3}$ on $\mathrm{Cu}(111)$ which was proposed to facilitate 
accelerated transport across the $\mathrm{Cu}(111)$ surface. ${ }^{8}$ However, it was soon recognized that other complexes such as $\mathrm{MS}_{2}$ and $\mathrm{M}_{2} \mathrm{~S}_{3}$ could also be relevant for $\mathrm{M}=\mathrm{Cu}$ or $\mathrm{Ag}$. ${ }^{6}$ A recent more comprehensive DFT study considered nine distinct $\mathrm{M}-\mathrm{S}$ complexes on $\mathrm{M}(111)$ for coinage metals $\mathrm{M}=\mathrm{Cu}, \mathrm{Ag}$, and $\mathrm{Au}$, as is appropriate for development of a comprehensive and reliable kinetic model for enhanced mass transport. ${ }^{18}$ The above observations motivate the comprehensive DFT study presented in this paper of $\mathrm{M}-\mathrm{S}$ complexes on $\mathrm{M}(100)$ surfaces for $\mathrm{M}=\mathrm{Cu}, \mathrm{Ag}$, and $\mathrm{Au}$ at very low coverages of $\mathrm{S}$. In this regime, behavior is not impacted by ordered adsorbate structures or reconstructions which can occur for higher $\mathrm{S}$ coverages. Of particular interest is comparison of behavior to that on M(111) surfaces.

The content of the paper is as follows. In Section 2, we describe methodology both for DFT analysis and the LTSTM experiments. In Section 3, we briefly review experimental studies of $\mathrm{S}$ on $\mathrm{Ag}(100)$ and $\mathrm{Ag}(111)$ surfaces where information is more complete than for other coinage metals. Next, in Section 4, we present our DFT results for the energetics of nine different $\mathrm{M}-\mathrm{S}$ complexes adsorbed on $\mathrm{M}(100)$ surfaces. A systematic comparison of energetics for gas-phase versus adsorbed complexes, within the framework of Hess's law, is presented in Section 5. The discussion in Section 6 elucidates the difference in behavior for $\mathrm{M}=\mathrm{Cu}$ and $\mathrm{Ag}$ versus $\mathrm{M}=\mathrm{Au}$, and also the difference in behavior for adsorbed complexes on $\mathbf{M}(100)$ and $\mathbf{M}(111)$ surfaces. Conclusions are provided in Section 7.

\section{Methodology}

For DFT analysis of extended periodic bulk and surface systems, it is most natural to use a plane-wave (PW) basis set. For such analyses, we use the VASP package (v5.4), ${ }^{19,20}$ the standard PAW potentials, ${ }^{21,22}$ and an energy cut-off of $280 \mathrm{eV}$. The surface is represented by a periodic array of slabs, separated by $1.2 \mathrm{~nm}$ of vacuum. Testing with a $400 \mathrm{eV}$ energy cutoff and a $2.1 \mathrm{~nm}$ vacuum thickness shows that resulting adsorbate formation energies (defined later) have converged with $0.01 \mathrm{eV}$ for the choices listed above. Lattice constants for the fcc metal substrates are taken as theoretical values. $\mathrm{S}$ and $\mathrm{M}-\mathrm{S}$ complexes are adsorbed on top of each slab (rather than on both sides). The total energy of the system is then minimized allowing both the adsorbate and metal substrate or slab atoms to relax, except for the bottom layer of the slab. We find that surface energetics converges slightly more quickly to behavior for thick slabs fixing a single layer versus, say, two layers at the bottom of the slab (but either choice is reasonable producing essentially identical result for sufficiently thick slabs). A related observation is that the deviation of the metal atoms at the center of the slab from their ideal bulk positions decreases rapidly as the thickness of the slab increases. We have tested that with adsorption of a $\mathrm{Cu}_{4} \mathrm{~S}_{5}$ complex, the root mean square of deviation of the bond lengths from the (theoretical) bulk lattice constant for such atoms decreases from $0.54 \%$ to $0.05 \%$ as the slab thickness $L$ increases from 4 to 7 . The convergence criterion requires that all forces are below $0.02 \mathrm{eV} \AA^{-1}$. The $\mathrm{PBE}^{23}$ functional is used for these slab calculations.

For our comparative analysis of the energetics of gas phase versus adsorbed complexes, we will utilize the results of DFT calculations for gas phase complexes carried out previously using both PW and atomic or Gaussian-type orbitals (GTO) as basis sets. Analysis for the latter was performed with NWChem software and with a variety of different sized basis sets. See ref. 18 for more details. We found excellent consistency for the PBE functional between the PW and GTO basis set analyses when using large quadruple zeta basis sets for the latter. This provides additional support for the reliability of these results.

For the LTSTM studies, the experimental instrumentation and procedures were similar to those used previously in analysis of $\mathrm{S}$ adsorption on $\mathrm{Cu}(111),{ }^{12} \mathrm{Cu}(100),{ }^{14} \mathrm{Ag}(111),{ }^{6} \mathrm{Au}(111),{ }^{16}$ and $\mathrm{Au}(100) .{ }^{17}$ In the current work, the single crystal $\mathrm{Ag}(100)$ sample was cleaned via several Ar+ sputtering (10-15 mA, $2 \mathrm{kV}, 10 \mathrm{~min})$ and annealing (700 K, $10 \mathrm{~min}$ ) cycles. Imaging by STM was performed at $5 \mathrm{~K}$ in UHV, at pressure $<6.0 \times 10^{-11}$ Torr. Sulfur was deposited in situ via an electrochemical $\mathrm{Ag}|\mathrm{AgI}| \mathrm{Ag}_{2} \mathrm{~S} \mid \mathrm{Pt}$ source. The sample was held at $300 \mathrm{~K}$ during $\mathrm{S}$ deposition, and then cooled to $5 \mathrm{~K}$ for measurement. Tunneling conditions during imaging were in the range $-3.00 \mathrm{~V}$ to $+3.00 \mathrm{~V}$ sample bias (VS), and 0.7 to $1.5 \mathrm{nA}$ tunneling current (I). The STM piezoelectric calibration was checked by comparing measured and theoretical dimensions for well-defined features. The measured separation of $\mathrm{S}$ adatoms in a $p(2 \times 2)$ adlayer along the close packed direction of $0.570 \pm 0.012 \mathrm{~nm}$ corresponds closely to the theoretical value of $2 a$, where $a=2.89 \mathrm{~nm}$ is the surface lattice constant for $\mathrm{Ag}(100)$. The heights of monoatomic steps on the $\mathrm{Ag}(100)$ surface were measured at $0.192 \pm 0.012 \mathrm{~nm}$ fairly consistent with the theoretical value of $a / \sqrt{2}$. The sulfur coverage $\left(\theta_{\mathrm{S}}\right)$ in monolayers was obtained by counting protrusions in STM images (associating each small protrusion with a single $\mathrm{S}$ adatom), and dividing by the areal density of atoms in a bulk $\mathrm{Ag}(100)$ plane. We present results for coverages of around 0.01 and 0.03 in units of absolute monolayers (ML).

\section{Illustrative case study: S on Ag surfaces at low coverages}

First, we review Scanning Tunneling Microscopy studies assessing S-enhanced mass transport and nanostructure decay on low-index Ag surfaces. In these studies, a submonolayer amount of Ag was first deposited on the low-index Ag surface, which had a terrace-step morphology with a moderate to low density of preexisting extended steps. Ag deposition creates a distribution of monolayer $\mathrm{Ag}$ islands. This surface was then exposed to controlled amounts of $\mathrm{S}$ resulting in low surface coverages of $\mathrm{S}$. The focus was on coarsening of $\mathrm{Ag}$ islands, and specifically on the decay of islands close to extended step edges by transfer of $\mathrm{Ag}$ from the island to the step edges. In experiments for $\mathrm{Ag}$ on $\mathrm{Ag}(111)$ at $300 \mathrm{~K},{ }^{6}$ a critical S coverage $\theta_{\mathrm{S}}^{\mathrm{c}} \approx 0.008 \mathrm{ML}$ was identified (specific to the sample used) 
which we associate with complete saturation by $\mathrm{S}$ of preexisting steps on the surface. For $\theta_{\mathrm{S}}<\theta_{\mathrm{S}}^{\mathrm{c}}$, S has no effect on coarsening as $\mathrm{S}$ is completely accommodated at step edges, but for $\theta_{\mathrm{S}}>\theta_{\mathrm{S}}^{\mathrm{c}}$ there is a dramatic enhancement associated with the presence of "excess" $\mathrm{S}$ on terraces which facilitates the formation of complexes. For $\theta_{\mathrm{S}} \approx 0.011 \mathrm{ML}$ at $300 \mathrm{~K}$, a $2000 \mathrm{~nm}^{2}$ island decays in about $5 \mathrm{~min}$ by transfer of $\mathrm{Ag}$ to nearby extended step edges versus about 550 min for decay of an island of this size when $\theta_{\mathrm{S}}<\theta_{\mathrm{S}}^{\mathrm{c}}$. Thus, the rate of decay increases by a factor of about 100. For higher coverages, island decay was so fast (occurring in less than the acquisition time for a single STM image) that it could not be quantified by STM imaging. In experiments for $\mathrm{Ag}$ on $\mathrm{Ag}(100)$ at $300 \mathrm{~K},{ }^{7}$ the decay of $10 \mathrm{~nm}^{2}$ islands roughly $5 \mathrm{~nm}$ away from an extended step was monitored as a function of $\theta_{\mathrm{S}}$. The decay time decreases from $70 \mathrm{~min}$ at $\theta_{\mathrm{S}} \approx 0.035 \mathrm{ML}$ to $30 \mathrm{~min}$ at $\theta_{\mathrm{S}} \approx 0.13 \mathrm{ML}$, corresponding to only a modest increase in decay rate by a factor of 2.3.

Next, we describe LTSTM studies undertaken with the goal of directly imaging and identifying Ag-S complexes on $\mathrm{Ag}(111)$ and $\mathrm{Ag}(100)$ surfaces which could be responsible for facilitating mass transport. LTSTM studies of Ag(111) exposed to S at $5 \mathrm{~K}^{15}$ were undertaken, noting that previous theory ${ }^{6}$ suggested the possible role of complexes such as $\mathrm{AgS}_{2}$ as well as $\mathrm{Ag}_{3} \mathrm{~S}_{3}$. As indicated in Section 1, these studies actually revealed the presence of $\mathrm{Ag}_{16} \mathrm{~S}_{13}$ and even larger $\mathrm{Ag}_{13 n+3} \mathrm{~S}_{9 n+4}$ complexes with $n>1$. The presence of such large complexes versus the smaller complexes suggested to facilitate mass transport in studies at $300 \mathrm{~K}$ can be understood as follows. At the very low temperature of $5 \mathrm{~K}$ used for LTSTM imaging, all S should be incorporated into the complex with the lowest chemical potential at $0 \mathrm{~K}$, with the caveat that kinetic limitations could impede formation of very large complexes. Indeed, our recent analysis of $\mathrm{M}-\mathrm{S}$ complexes on $\mathrm{M}(111)$ indicates a trend of decreasing chemical potential at $0 \mathrm{~K}$ for increasing $\mathrm{Ag}-\mathrm{S}$ complex size consistent with the observation of large complexes. ${ }^{18}$ To assess behavior for $T>0$, Russell et al. ${ }^{15}$ used a kinetic 'polymerization' model to argue that the equilibrium population, $P_{n}$, of linear aggregates of $n$ "monomer units" with neighboring attractive bond strength $\phi>0$ satisfies $P_{n} \approx \rho \exp \left[+\phi /\left(k_{\mathrm{B}} T\right)\right] P_{n-1}$ where the monomer density $\rho \ll 1$ increases with $\theta_{\mathrm{S}}$. This result supports the picture that upon increasing $T$, there is a switch from dominance of large complexes to small complexes.

To provide a more complete experimental assessment of behavior on Ag surfaces, we briefly present results of a new LTSTM analysis of $\mathrm{Ag}(100)$ exposed to $\mathrm{S}$ at $5 \mathrm{~K}$. The key observation is that these studies reveal a lack of $\mathrm{Ag}-\mathrm{S}$ complex formation, and instead just isolated $\mathrm{S}$ adatoms are observed on the $\mathrm{Ag}(100)$ surface. Detailed confirmation that the dots surrounded by a darker ring are single $S$ adatoms have been presented elsewhere. ${ }^{24}$ However, exactly the same features were observed in imaging of isolated $\mathrm{S}$ adatoms on $\mathrm{Cu}(100){ }^{14}$

Fig. 1 shows LTSTM images comparing behavior on $\mathrm{Ag}(100)$ and $\mathrm{Ag}(111)$ surfaces. Fig. 1(a and b) reveal isolated $\mathrm{S}$ adatoms on $\mathrm{Ag}(100)$ for $\mathrm{S}$ coverages of $0.01 \mathrm{ML}$ and 0.03 ML. Fig. 1(c) shows a distribution of $\mathrm{Ag}_{13 n+3} \mathrm{~S}_{9 n+4}$ complexes for $n>1$ on
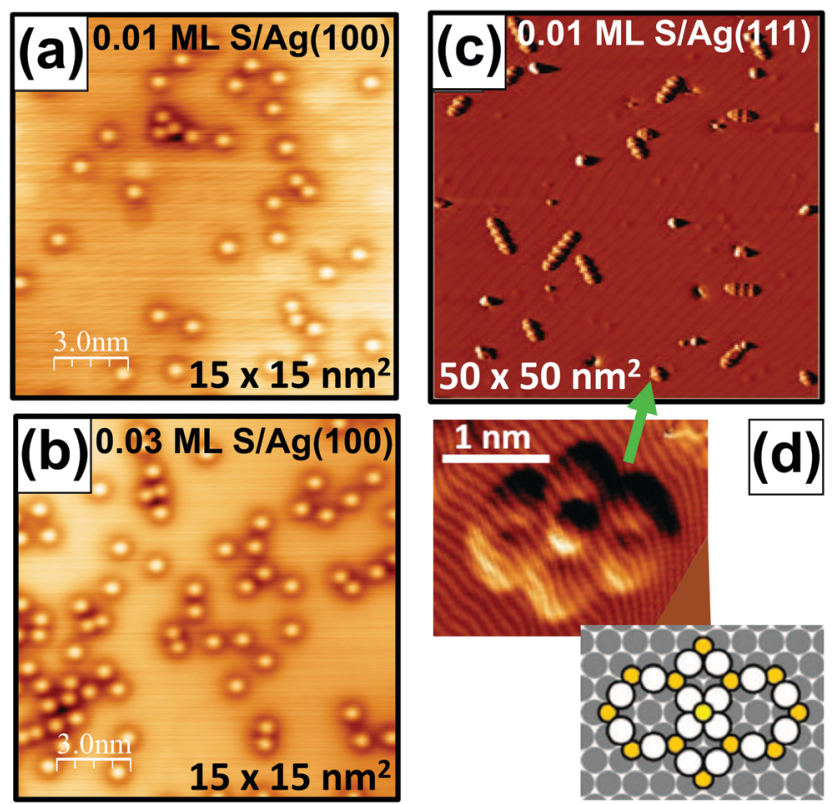

Fig. 1 LTSTM images of $S$ on low-index Ag surfaces. ( $a$ and $b$ ) $S$ adatoms on $\mathrm{Ag}(100)$ at: (a) $0.01 \mathrm{ML} \mathrm{S}$; and (b) $0.03 \mathrm{ML} \mathrm{S}$. (c) $\mathrm{Ag}_{13 n+3} \mathrm{~S}_{9 n+4}$ complexes on $\mathrm{Ag}(111)$ at $0.01 \mathrm{ML} \mathrm{S}^{15}$ (d) Expanded image and a schematic of an $\mathrm{Ag}_{16} \mathrm{~S}_{13}$ complex. ${ }^{15}$ Copyright American Institute of Physics 2013 for (c and d).

$\mathrm{Ag}$ (111) for 0.01 ML S, and Fig. 1(d) provides an close-up image of a single $\mathrm{Ag}_{16} \mathrm{~S}_{13}$ complex and a schematic of its structure.

\section{Energetics of adsorbed $\mathrm{M}-\mathrm{S}$ complexes on $M(100)$}

DFT analysis is applied to characterize the energetics of various $\mathrm{M}_{m} \mathrm{~S}_{n}$ complexes adsorbed on $\mathrm{M}(100)$ surfaces. Most calculations use a $(4 \times 4)$ lateral supercell which is generally sufficiently large that there are no direct interconnections between complexes. For $\mathrm{M}=\mathrm{Au}$, this analysis does not incorporate the hex reconstruction of extended $\mathrm{Au}(100)$ surfaces. This is not a significant shortcoming since exposure of clean $\mathrm{Au}(100)$ to $\mathrm{S}$, with possible subsequent formation of an ordered $S$ adlayer and/or of $\mathrm{M}-\mathrm{S}$ complexes, lifts this reconstruction. In general, there can be multiple metastable configurations for adsorbed complexes, so determination of the most stable adsorbed structure is non-trivial, especially for larger $m$ and $n$. However, we have reasonable confidence that the lowest energy configurations have been identified. Fig. 2 shows top views of the proposed most stable configuration of various adsorbed $\mathrm{M}-\mathrm{S}$ complexes based upon DFT-PBE.

\section{Surface atomization energy for complexes}

We consider the energy required to completely fragment adsorbed (ads) complexes $\mathbf{M}_{m} \mathbf{S}_{n}$ into isolated $\mathbf{M}$ adatoms and isolated chemisorbed $\mathrm{S}$ atoms remaining on the surface,

$$
E_{\mathrm{a}}\left(\mathrm{M}_{m} \mathrm{~S}_{n}\right)(\mathrm{ads})=m E[\mathrm{M}(\mathrm{ads})]+n E[\mathrm{~S}(\mathrm{ads})]-E\left[\mathrm{M}_{m} \mathrm{~S}_{n}(\mathrm{ads})\right]
$$




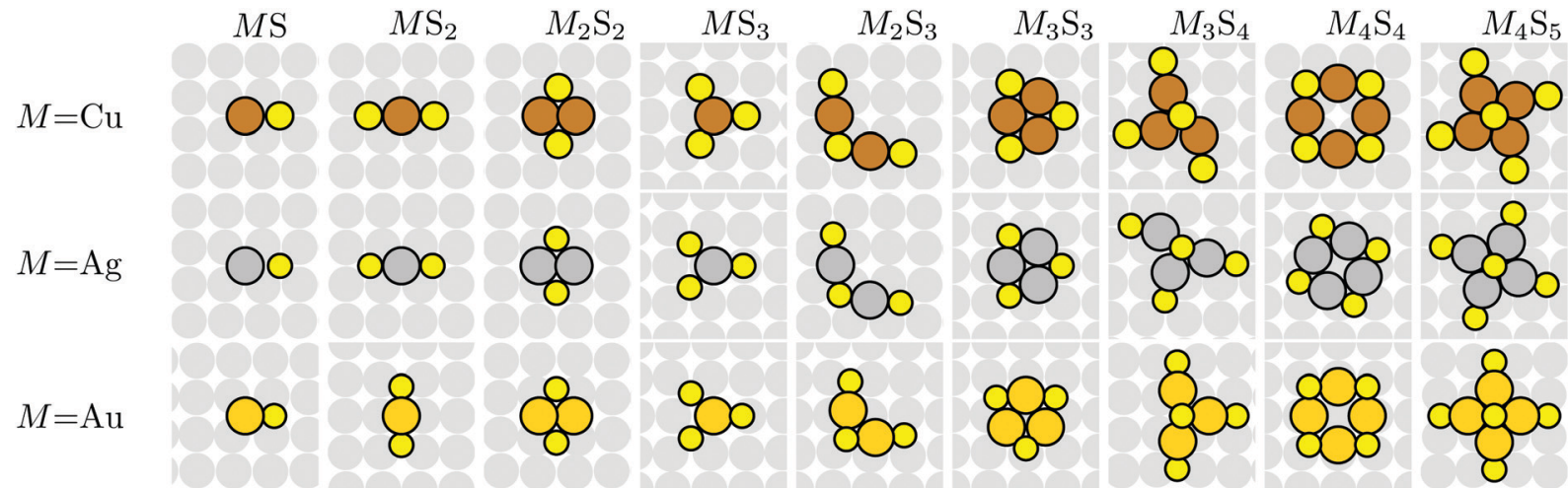

Fig. 2 Top view of M-S complexes on M(100) surfaces. Top: $\mathrm{Cu}$ (brown); middle: Ag (grey); bottom: Au (gold). The diameter of M atoms is taken as the nearest-neighbor distance in the bulk. S (yellow) has diameter taken as the $\mathrm{S}_{2}$ bond length. Structures are obtained from PBE VASP. Configurations of a specific complex, $M_{m} S_{n}($ ads), are mostly similar for different $M$, with slight changes in bond lengths and angles.

Table 1 Surface atomization energies, $E_{a}\left(M_{m} S_{n}\right)$ (ads) (in eV), for various adsorbed complexes, $M_{m} S_{n}$, on the (100) surface obtained from VASP using the PBE functional

\begin{tabular}{lllllllllll}
\hline & $\mathrm{S}_{2}$ & $\mathrm{MS}$ & $\mathrm{MS}_{2}$ & $\mathrm{M}_{2} \mathrm{~S}_{2}$ & $\mathrm{MS}_{3}$ & $\mathrm{M}_{2} \mathrm{~S}_{3}$ & $\mathrm{M}_{3} \mathrm{~S}_{3}$ & $\mathrm{M}_{3} \mathrm{~S}_{4}$ & $\mathrm{M}_{4} \mathrm{~S}_{4}$ & $\mathrm{M}_{4} \mathrm{~S}_{5}$ \\
\hline $\mathrm{Cu}(100)$ & -1.82 & -0.15 & 0.02 & -1.15 & -1.84 & 0.11 & 0.00 & 0.50 & 0.38 \\
$\mathrm{Ag}(100)$ & -0.96 & -0.17 & 0.00 & -0.98 & -1.54 & 0.10 & 0.27 & 0.43 & 0.55 \\
$\mathrm{Au}(100)$ & -0.16 & -0.37 & 0.37 & -1.85 & -1.72 & 0.57 & 0.04 & 1.22 & 1.00 & 2.36
\end{tabular}

with $E[\mathrm{X}(\mathrm{ads})]=E[\mathrm{X}(\mathrm{ads})+\mathrm{slab}]-E[\mathrm{slab}]$, where $E[\mathrm{X}(\mathrm{ads})+$ $\mathrm{slab}]$ is the energy of a system with a species $\mathrm{X}$ adsorbed on the substrate, and $E[$ slab] the energy of the substrate (i.e., the slab), with both the clean slab and the system with adsorbate optimized independently. Table 1 lists the surface atomization energies for the adsorbed complexes shown in Fig. 2 (as well as the atomization energy for $\left.\mathrm{S}_{2}\right)$. Note that $E_{\mathrm{a}}\left(\mathrm{M}_{m} \mathrm{~S}_{n}\right)($ ads $)>0$ implies that the complex is stable against complete fragmentation into atomic constituents which remain as isolated adsorbed species on terraces of the surface. In this case, $E_{\mathrm{a}}\left(\mathrm{M}_{m} \mathrm{~S}_{n}\right)(\mathrm{ads})>0$ measures the strength of the binding within the adsorbed complex. A negative surface atomization energy, $E_{\mathrm{a}}\left(\mathrm{M}_{m} \mathrm{~S}_{n}\right)(\mathrm{ads})<0$, implies that the adsorbed complex is unstable against such complete fragmentation. For $E_{\mathrm{a}}\left(\mathrm{M}_{m} \mathrm{~S}_{n}\right)(\mathrm{ads})<0$, the corresponding complex configurations shown in Fig. 2 should be regarded as metastable (i.e., corresponding to local energy minima).

We emphasize below that a different and more demanding criterion for stability of adsorbed complexes than that described above is typically more appropriate in an experimental context. However, based upon the above prescription, the general trend revealed by Table 1 is that smaller complexes tend to be unstable in that they have negative surface atomization energies, but larger ones become stable. In addition to stability (or otherwise) against complete fragmentation into atomic components, one should also assess stability for complexes with $E_{\mathrm{a}}\left(\mathrm{M}_{m} \mathrm{~S}_{n}\right)$ (ads) $>0$ with against decomposition into, say, two fragments (each with $E_{\mathrm{a}}\left(\mathrm{M}_{m} \mathrm{~S}_{n}\right)($ ads) $\geq 0$ ) which remain on the terrace on the surface. Possible fragmentation processes within this class include $\mathrm{M}_{4} \mathrm{~S}_{5} \rightarrow \mathrm{M}_{4} \mathrm{~S}_{4}+\mathrm{S}, \mathrm{M}_{4} \mathrm{~S}_{5} \rightarrow \mathrm{M}_{3} \mathrm{~S}_{3}+\mathrm{MS}_{2}$, and $\mathrm{M}_{3} \mathrm{~S}_{4} \rightarrow \mathrm{M}_{3} \mathrm{~S}_{3}+\mathrm{S}$. However, none of these processes is energetically favorable as the sum of $E_{\mathrm{a}}\left(\mathrm{M}_{m} \mathrm{~S}_{n}\right)(\mathrm{ads})$ for the fragmentation products is less than $E_{\mathrm{a}}\left(\mathrm{M}_{m} \mathrm{~S}_{n}\right)$ (ads) for the larger complex (where we use that $\left.E_{\mathrm{a}}(\mathrm{S})(\mathrm{ads})=0\right)$.

\section{Formation energy of complexes assembled from $S$ adatoms and bulk $M$}

Rather than the surface atomization energy described above, generally the most appropriate measure of the stability of adsorbed complexes is their formation energy from $\mathrm{S}$ adatoms on terraces, and from $\mathrm{M}$ atoms extracted from the substrate (e.g., via detachment of $\mathrm{M}$ atoms at kink sites along step edges). ${ }^{6,8,13,18,25}$ Schematically, this reaction is represented as

$$
m \mathrm{M}(\text { substrate })+n \mathrm{~S}(\text { ads }) \stackrel{E_{\mathrm{f}}(\mathrm{ads})}{\longrightarrow} \mathrm{M}_{m} \mathrm{~S}_{n}(\mathrm{ads}) .
$$

Thus, the formation energy gauges the stability of the complex against decomposition where $\mathbf{M}$ is reincorporated into the substrate (which results in a significant energy reduction relative to remaining as isolated $\mathrm{M}$ adatoms on terraces), and where $\mathrm{S}$ remain as isolated adatoms on terraces. The motivation for assigning $\mathrm{S}$ adatoms as the "reference state" is that $\mathrm{S}$ at low coverages do not cluster into islands on $\mathrm{M}(100)$ surfaces. (If there existed sufficiently strong attractive interactions leading to $\mathrm{S}$ clustering which was preferred over isolated $\mathrm{S}$ adatoms, then the clustered state would be the appropriate lower energy reference state. However, this is not the case.)

Although our primary interest is in behavior at very low $T=5 \mathrm{~K}$, it is convenient to first define the formation energy, $E_{\mathrm{f}}\left(\mathrm{M}_{m} \mathrm{~S}_{n}\right)(\mathrm{ads})$, for the complex $\mathrm{M}_{m} \mathrm{~S}_{n}$ for general finite $T$ via

$E_{\mathrm{f}}\left(\mathbf{M}_{m} \mathbf{S}_{n}\right)(\mathrm{ads})=F\left(\mathbf{M}_{m} \mathbf{S}_{n}+\right.$ slab $)-F($ slab $)-m \mu_{\mathbf{M}}-n \mu_{\mathrm{S}}$, 
where again we have indicated that the substrate is represented as a slab in our DFT analysis. Here, $F$ denotes a free energy, $\mu_{\mathbf{M}}$ denotes the chemical potential of $\mathbf{M}$, and $\mu_{\mathrm{S}}$ denotes the chemical potential of $\mathrm{S}$ in an initial state before complex formation which involves a chemisorbed $S$ adlayer on the metal substrate, as discussed in more detail below. With the use of free energies and chemical potentials in eqn (3) rather than just energies at $T=0 \mathrm{~K}$ ), there is no ambiguity regarding the choice of reference states. ${ }^{18} \mathrm{M}$ is regarded as being equilibrated with the substrate, so that $\mu_{\mathbf{M}}$ is the same for isolated adatoms, kink and step edge atoms, and bulk atoms. Thus, $\mu_{\mathrm{M}}$ can be determined from bulk metal calculations. However, we prefer to use slab calculations for consistency with determination of other energies, so that we systematically account for quantum size effects in thin slabs. ${ }^{26}$ Specifically, we calculate $\mu_{M}$ from the slope of a linear fit to the total energy of clean slabs versus slab thickness $L$, using the same range of $L$ as that used to assess energetics of adsorbed complexes (typically 4 to 7 layers). In the initial state before complex formation, $\mathrm{S}$ is regarded as being equilibrated with a low coverage chemisorbed adlayer on a nonreactive metal substrate (constrained so that metal atoms cannot be extracted to form complexes).

Given the presence of primarily repulsive interactions within this $\mathrm{S}$ adlayer, $\mu_{\mathrm{S}}$ increases somewhat with $\theta_{\mathrm{S}}$. Thus, one natural strategy to simplify the interpretation of behavior is to select a specific S coverage which is sufficiently low that these interactions are not significant (but not so low that configurational entropy of the adlayer provides a significant contribution to the chemical potential). There is a broad range of coverage for which these conditions are satisfied. See the ESI for ref. 17. However, such analysis is computationally costly as it requires very large unit cells for complexes with many $\mathrm{S}$ atoms.

Thus, instead to achieve a major reduction in computational cost, we first we present results using a fixed $(4 \times 4)$ supercell, so that the corresponding complex coverage is fixed at 1/16 ML, but the sulfur coverage of $n / 16 \mathrm{ML}$ varies for different $n$. Formation energies for the adsorbed complexes in Fig. 2 (as well as the formation energy for $\mathbf{M}$ ) are summarized in Table 2. We claim that these should correspond to $E_{\mathrm{f}}$ with a low fixed $\mathrm{S}$ coverage. To confirm this claim, we have performed additional analysis of formation energies for a subset of complexes on $\mathrm{Cu}(100)$ for various fixed S coverages (the lowest coverage requiring largest unit cell). Results are shown in Table 4 in the Appendix A. One generally finds excellent agreement with the results in Table 2 for fixed supercell size. The one exception is for $\mathrm{M}_{4} \mathrm{~S}_{5}$ complexes, where 5/16 ML S coverage for the $(4 \times 4)$ supercell is too high to avoid significant lateral interactions. However, using a larger $(2 \sqrt{5} \times 2 \sqrt{5})$ supercell, one finds the result agrees with that for fixed low $\mathrm{S}$ coverage in Appendix A. For convenient comparison with the results Table 2 for $\mathrm{M}(100)$ surfaces, formation energies for analogous complexes on $\mathrm{M}(111)$ surfaces are listed in the Appendix B.

A negative formation energy means that the complex is stable against fragmentation where the $\mathrm{M}$ atoms are incorporated into the bulk, and where the $\mathrm{S}$ atoms remain as adatoms on terraces. A positive formation energy means that it is unstable. Note that for positive formation energies, the (low) population of such complexes on the surface is given by the corresponding Boltzmann factor. For negative formation energies, essentially all $\mathrm{S}$ adsorbed on terraces should be incorporated into such complexes. The results in Table 2 show that all formation energies are positive for $\mathrm{M}=\mathrm{Ag}$ and $\mathrm{Cu}$, entirely consistent with experimental results indicating an absence of M-S complexes on M(100) surfaces for those metals. However, the formation energy for $\mathrm{M}_{4} \mathrm{~S}_{5}$ is quite low, so those complexes should have a non-negligible population at say $300 \mathrm{~K}$, although likely significant mobility would preclude imaging at that temperature. Furthermore, the $\mathrm{Cu}_{4} \mathrm{~S}_{5}$ motif has been identified as a component of the $(\sqrt{17} \times \sqrt{17}) R 14^{\circ}$ reconstruction on $\mathrm{Cu}(100)$ at high $\mathrm{S}$ coverages. ${ }^{14,27}$

In marked contrast, formation energies are negative for multiple complexes on $\mathrm{Au}(100)$. To determine the relative stability of such complexes, we define a final state chemical potential of the $\mathrm{S}$ atom in a complex through $\mu_{\mathrm{S}}\left(\mathrm{M}_{n} \mathrm{~S}_{n}\right)=$ $\left[F\left(\mathrm{M}_{m} \mathrm{~S}_{n}+\mathrm{slab}\right)-F(\mathrm{slab})-m \mu_{\mathrm{M}}\right] / n$. Note that from eqn (3), the difference between the final and initial state chemical potentials of $\mathrm{S}$ in a metal-sulfur complex $\mathrm{M}_{m} \mathrm{~S}_{n}$ and in a $S$ adlayer, respectively, can be simply obtained from the formation energy through $\Delta \mu_{\mathrm{S}}\left(\mathrm{M}_{m} \mathrm{~S}_{n}\right)=\mu_{\mathrm{S}}\left(\mathrm{M}_{m} \mathrm{~S}_{n}\right)-\mu_{\mathrm{S}}=$ $E_{\mathrm{f}}\left(\mathrm{M}_{m} \mathrm{~S}_{n}\right)(\mathrm{ads}) / n$. Thus, the formation energy, after dividing by $n$, provides direct information on the relative stability of various complexes. The complex with the lowest $\Delta \mu_{\mathrm{S}}\left(\mathrm{M}_{n} \mathrm{~S}_{n}\right)$ would be thermodynamically preferred. Applying this criterion, the most stable complex on $\mathrm{Au}(100)$ is $\mathrm{Au}_{4} \mathrm{~S}_{5}$, which is believed to correspond to the feature observed in LTSTM studies which existed within or at the edges of $p(2 \times 2) \mathrm{S}$ islands. ${ }^{17}$ In addition, $\mathrm{AuS}_{2}, \mathrm{Au}_{3} \mathrm{~S}_{4}$ and $\mathrm{Au}_{2} \mathrm{~S}_{3}$ complexes, which can be viewed as incomplete $\mathrm{Au}_{4} \mathrm{~S}_{5}$ complexes, were also observed. As all of these complexes have negative formation energies, the predictions of our DFT analysis are in excellent agreement with experiments. DFT energetics of stable $\mathrm{Au}-\mathrm{S}$ complexes were reported previously in ref. 17 and are consistent with the results reported here. Again, we note that although clean $\mathrm{Au}(100)$ has a hex reconstruction, this is lifted by $\mathrm{S}$ adsorption and complex formation aiding the veracity of our analysis.

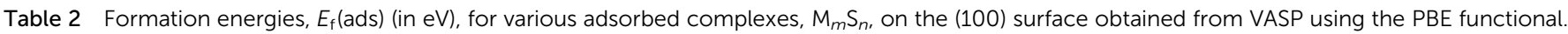
Supercells used are $(4 \times 4)$, except for $\mathrm{M}_{4} \mathrm{~S}_{5}$ where results with larger $(2 \sqrt{5} \times 2 \sqrt{5}) R 27^{\circ}$ are also reported as the second number in the column

\begin{tabular}{|c|c|c|c|c|c|c|c|c|c|c|}
\hline & M & MS & $\mathrm{MS}_{2}$ & $\mathrm{M}_{2} \mathrm{~S}_{2}$ & $\mathrm{MS}_{3}$ & $\mathrm{M}_{2} \mathrm{~S}_{3}$ & $\mathrm{M}_{3} \mathrm{~S}_{3}$ & $\mathrm{M}_{3} \mathrm{~S}_{4}$ & $\mathrm{M}_{4} \mathrm{~S}_{4}$ & $\mathrm{M}_{4} \mathrm{~S}_{5}$ \\
\hline $\mathrm{Cu}(100)$ & 0.57 & 0.72 & 0.56 & 2.32 & 2.42 & 1.05 & 1.80 & 1.30 & 2.03 & $0.30,1.25$ \\
\hline $\operatorname{Ag}(100)$ & 0.42 & 0.58 & 0.42 & 1.82 & 1.96 & 0.73 & 1.01 & 0.85 & 1.18 & $0.15,0.88$ \\
\hline $\operatorname{Au}(100)$ & 0.19 & 0.57 & -0.17 & 2.20 & 1.92 & -0.20 & 0.71 & -0.47 & 0.07 & $-1.31,-0.57$ \\
\hline
\end{tabular}




\section{Relating gas phase and surface energetics: Hess's law}

It is natural to compare at least trends in stability for $\mathrm{M}-\mathrm{S}$ complexes adsorbed on surfaces with those in the gas phase. A systematic approach to relate these energies comes from considering an indirect pathway for formation of adsorbed complexes which involves three steps: (1) desorption of atomic constituents from the surface; (2) formation of the complex in the gas phase; and (3) adsorption of the complex onto the surface. Schematically, this process is described by

$$
\begin{aligned}
m \mathrm{M}(\text { bulk })+n \mathrm{~S}(\text { ads }) & \stackrel{\Delta E_{1}}{\longrightarrow} \\
\longrightarrow & m \mathrm{M}(\text { gas })+n \mathrm{~S}(\text { gas }) \stackrel{\Delta E_{2}}{\longrightarrow} \mathrm{M}_{m} \mathrm{~S}_{n}(\text { gas }) \\
\stackrel{\Delta E_{3}}{\longrightarrow} & M_{m} \mathrm{~S}_{n}(\text { ads }),
\end{aligned}
$$

and also illustrated in Fig. 3 for the case $m=4$ and $n=5$. Hess's law in thermochemistry states that the overall enthalpy change (obtained by summing contributions, $\Delta E_{j}$ from the three steps $j=1-3)$ is equal to the enthalpy change, $E_{\mathrm{f}}$ (ads), associated with the direct formation pathway on the surface. The energy changes in the different steps are

$$
\begin{aligned}
\Delta E_{1} & =-n E_{\mathrm{ad}}(\mathrm{S})+m E_{\mathrm{c}}(\mathrm{M}), \\
\Delta E_{2} & =-E_{\mathrm{a}}\left(\mathrm{M}_{m} \mathrm{~S}_{n}\right)(\text { gas }), \\
\Delta E_{3} & =E_{\mathrm{ad}}\left(M_{\mathrm{m}} \mathrm{S}_{n}\right) .
\end{aligned}
$$

Here $E_{\mathrm{ad}}(\mathrm{X})=E[\mathrm{X}(\mathrm{ads})]-E[\mathrm{X}($ gas $)]$ denotes the adsorption energy for species $\mathrm{X}=\mathrm{S}$ or $\mathrm{M}_{m} \mathrm{~S}_{n}$. The adsorption process is generally exothermic, so that $E_{\mathrm{ad}}$ is negative. $E_{\mathrm{c}}(\mathrm{M})$ denotes the cohesive energy of bulk $\mathrm{M}$, and $E_{\mathrm{a}}\left(\mathrm{M}_{m} \mathrm{~S}_{n}\right)$ (gas) denotes the atomization energy of the gas-phase $\mathbf{M}_{m} \mathbf{S}_{n}$ complex.

We note that there is no unique choice for the pathway for complex formation, or for the individual steps in the pathway. The current choice is motivated by the following appealing features: (i) $\Delta E_{1}$ is readily determined by quantities, $E_{\mathrm{ad}}(\mathrm{S})$ and $E_{\mathrm{c}}(\mathrm{M})$, which are independent of the complex; (ii) $\Delta E_{2}$ is simply
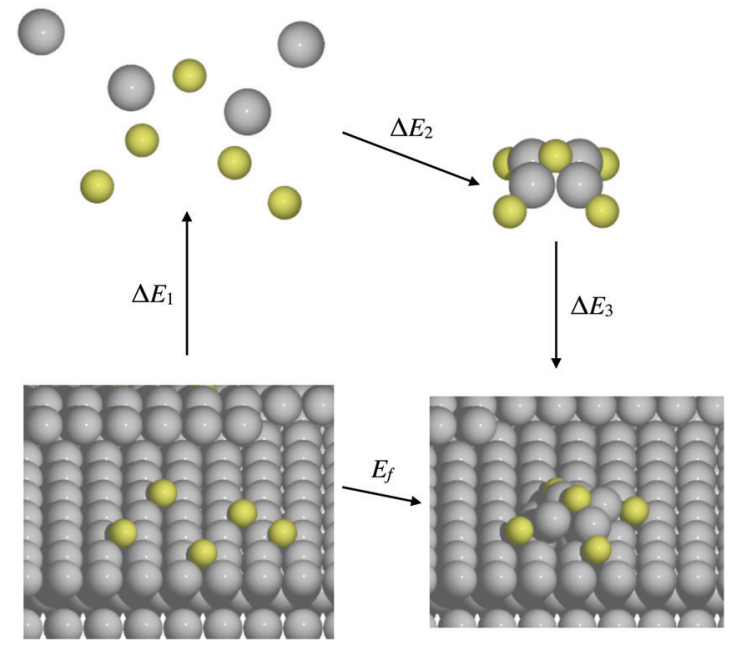

Fig. 3 Schematic for Hess's law specifically illustrating the case of $M_{4} S_{5}$. the atomization energy of the gas-phase complex, which is a familiar concept in gas-phase chemistry and has been obtained previously in ref. 18; and (iii) $\Delta E_{3}$ is the adsorption energy for the complex, a central concept in surface chemistry.

In Table 3, we tabulate the $\Delta E_{j}$ in each individual step of eqn (4) (or Fig. 3). Step 1 is destabilizing while steps 2 and 3 are stabilizing in the formation of adsorbed complexes. PBE values of $\Delta E_{1}$ are calculated from the theoretical bulk cohesive energies, $E_{\mathrm{c}}^{\mathrm{M}}=3.47,2.52$, and $3.04 \mathrm{eV}$ for $\mathrm{Cu}, \mathrm{Ag}$, and $\mathrm{Au}$, respectively, and from theoretical $\mathrm{S}$ adsorption energies, $E_{\text {ad }}(\mathrm{S})=-4.97,-4.04$, and $-3.78 \mathrm{eV}$ for $\mathrm{Cu}(100), \mathrm{Ag}(100)$, and $\mathrm{Au}(100)$, respectively. The negative of the gas phase atomization energy, $\Delta E_{2}$, is reported in the second column where these values were obtained from our previous study of gas phase energetics in ref. 18. Note that the gas phase atomization energies are far larger in magnitude than the corresponding surface atomization energies. Adsorption energies, $\Delta E_{3}=E_{\mathrm{ad}}\left(\mathrm{M}_{m} \mathrm{~S}_{n}\right)$, for complexes are listed in the third column. In general, there is not a strong correlation between the gas phase atomization energy and the surface atomization and formation energies. This is not surprising particularly for the latter which are relatively small quantities determined by differences between much larger quantities. Also, a stronger M-S interaction increases the magnitude of both the desorption energies in step 1 and the adsorption energies in step 3, precluding a clear trend in the formation energies.

Table 3 Decomposition of the formation energy (in eV) of metal-sulfur complex on $\mathrm{M}(100)$ surfaces into three steps: (1) desorption; (2) gas phase

\begin{tabular}{|c|c|c|c|c|}
\hline Complex & $\Delta E_{1}$ & $\Delta E_{2}$ & $\Delta E_{3}$ & $E_{\mathrm{f}}(\mathrm{ads})$ \\
\hline CuS & 8.43 & -3.23 & -4.48 & 0.71 \\
\hline $\mathrm{CuS}_{2}$ & 13.34 & -5.82 & -6.96 & 0.55 \\
\hline $\mathrm{Cu}_{2} \mathrm{~S}_{2}$ & 16.81 & -10.02 & -4.48 & 2.31 \\
\hline $\mathrm{CuS}_{3}$ & 18.23 & -7.75 & -8.07 & 2.41 \\
\hline $\mathrm{Cu}_{2} \mathrm{~S}_{3}$ & 21.70 & -11.87 & -8.79 & 1.04 \\
\hline $\mathrm{Cu}_{3} \mathrm{~S}_{3}$ & 25.17 & -16.63 & -6.76 & 1.78 \\
\hline $\mathrm{Cu}_{3} \mathrm{~S}_{4}$ & 30.07 & -17.34 & -11.44 & 1.28 \\
\hline $\mathrm{Cu}_{4} \mathrm{~S}_{4}$ & 33.54 & -23.06 & -8.46 & 2.01 \\
\hline $\mathrm{Cu}_{4} \mathrm{~S}_{5}$ & 37.36 & -22.41 & -14.67 & 0.28 \\
\hline $\mathrm{AgS}$ & 6.58 & -2.46 & -3.54 & 0.58 \\
\hline $\mathrm{AgS}_{2}$ & 10.60 & -4.52 & -5.66 & 0.42 \\
\hline $\mathrm{Ag}_{2} \mathrm{~S}_{2}$ & 13.12 & -7.44 & -3.86 & 1.81 \\
\hline $\mathrm{AgS}_{3}$ & 14.61 & -5.78 & -6.87 & 1.96 \\
\hline $\mathrm{Ag}_{2} \mathrm{~S}_{3}$ & 17.13 & -9.06 & -7.33 & 0.73 \\
\hline $\mathrm{Ag}_{3} \mathrm{~S}_{3}$ & 19.65 & -12.69 & -5.95 & 1.00 \\
\hline $\mathrm{Ag}_{3} \mathrm{~S}_{4}$ & 23.66 & -13.32 & -9.50 & 0.84 \\
\hline $\mathrm{Ag}_{4} \mathrm{~S}_{4}$ & 26.19 & -17.49 & -7.53 & 1.16 \\
\hline $\mathrm{Ag}_{4} \mathrm{~S}_{5}$ & 29.42 & -17.34 & -11.95 & 0.13 \\
\hline $\mathrm{AuS}$ & 6.83 & -2.94 & -3.34 & 0.56 \\
\hline $\mathrm{AuS}_{2}$ & 10.59 & -5.92 & -4.85 & -0.18 \\
\hline $\mathrm{Au}_{2} \mathrm{~S}_{2}$ & 13.63 & -8.49 & -2.92 & 2.22 \\
\hline $\mathrm{AuS}_{3}$ & 14.35 & -7.51 & -4.93 & 1.91 \\
\hline $\mathrm{Au}_{2} \mathrm{~S}_{3}$ & 17.39 & -11.51 & -6.07 & -0.20 \\
\hline $\mathrm{Au}_{3} \mathrm{~S}_{3}$ & 20.43 & -14.92 & -4.81 & 0.69 \\
\hline $\mathrm{Au}_{3} \mathrm{~S}_{4}$ & 24.19 & -16.41 & -8.26 & -0.49 \\
\hline $\mathrm{Au}_{4} \mathrm{~S}_{4}$ & 27.22 & -21.60 & -5.54 & 0.09 \\
\hline $\mathrm{Au}_{4} \mathrm{~S}_{5}$ & 30.12 & -20.87 & -10.53 & -1.27 \\
\hline
\end{tabular}
formation; and (3) adsorption. The gas phase atomization energy corresponds to $-\Delta E_{2}$, and the adsorption energy for complexes onto the $M(100)$ surface corresponds to $\Delta E_{3}$. Results from VASP using the PBE functional 
Finally, we provide some specific examples comparing gas phase and surface behavior. As noted above, in general, trends in gas phase stability do not correlate with those for adsorbed complexes. Consider first the sequence of complexes $\mathrm{Au}_{4} \mathrm{~S}_{5}$, $\mathrm{Au}_{4} \mathrm{~S}_{4}, \mathrm{Au}_{3} \mathrm{~S}_{4}, \mathrm{Au}_{3} \mathrm{~S}_{3}, \mathrm{Au}_{2} \mathrm{~S}_{3}$, and $\mathrm{AuS}_{3}$. For adsorbed species, there is a alternating pattern of negative (stable) and positive (unstable) $E_{\mathrm{f}}\left(\mathrm{M}_{m} \mathrm{~S}_{n}\right)$ (ads). This pattern is also reflected in the surface atomization energies which alternate from higher to lower values. The most stable adsorbed complex in this set is $\mathrm{Au}_{4} \mathrm{~S}_{5}$ which has the lowest (relative) chemical potential $\Delta \mu_{\mathrm{S}}\left(\mathrm{M}_{4} \mathrm{~S}_{5}\right)=-0.32 \mathrm{eV}$. In contrast, for these complexes in the gas phase, $\mathrm{Au}_{4} \mathrm{~S}_{5}$ is unstable against detachment of an $\mathrm{S}$ (as its atomization energy, $-\Delta E_{2}$, is lower than that for $\left.\mathrm{Au}_{4} \mathrm{~S}_{4}\right)$. Similarly, there is a relatively low cost of $1.49 \mathrm{eV}$ to detach an $\mathrm{S}$ from $\mathrm{Au}_{3} \mathrm{~S}_{4}$ in the gas phase, despite the feature that this complex is quite stable when adsorbed. Another general feature is that $\mathrm{Ag}-\mathrm{S}$ complexes are less stable than $\mathrm{Cu}-\mathrm{S}$ complexes in the gas phase, but they have lower (more negative) formation energies than $\mathrm{Cu}-\mathrm{S}$ complexes on the surface. Overall, Ag-S complexes have weaker adsorption energies, a feature which does not enhance their stability when adsorbed relative to $\mathrm{Cu}-\mathrm{S}$ complexes. However, the energy cost to extract $\mathrm{Cu}$ from the substrate is much higher than for $\mathrm{Ag}$, and the adsorption of $\mathrm{S}$ on $\mathrm{Cu}(100)$ is stronger than on $\mathrm{Ag}(100)$. These latter factors dominate the relative values of formation energies.

\section{Discussion: comparison of behavior on $M(100)$ and $M(111)$ surfaces}

In this section, we return to one of our key goals of comparing the stability of $\mathrm{M}-\mathrm{S}$ complexes on $\mathrm{M}(111)$ and $\mathrm{M}(100)$ surfaces. For this purpose, the decomposition of energies in Section 5 using Hess's law is particularly instructive since the second step involving gas phase formation and the associated energy, $\Delta E_{2}$, is independent of the type of surface. As discussed below, a key factor controlling the differing behavior for the $\mathrm{M}(100)$ and $\mathrm{M}(111)$ surfaces is the difference in adsorption energies for (isolated) $\mathrm{S}$ adatoms. For $\mathrm{Cu}$ and $\mathrm{Ag}$, there is a strong preference for adsorption on (100) over (111) surfaces: $E_{\mathrm{ad}}(\mathrm{S})=$ $-4.97 \mathrm{eV}$ versus $-4.40 \mathrm{eV}$ for $\mathrm{Cu}(100)$ versus $\mathrm{Cu}(111)$; and $E_{\mathrm{ad}}(\mathrm{S})=$ $-4.04 \mathrm{eV}$ versus $-3.64 \mathrm{eV}$ for $\mathrm{Ag}(100)$ versus $\mathrm{Ag}(111)$. In contrast, values of $E_{\mathrm{ad}}(\mathrm{S})=-3.78 \mathrm{eV}$ versus $-3.69 \mathrm{eV}$ for $\mathrm{Au}(100)$ versus $\mathrm{Au}(111)$, are much closer.

The stronger adsorption of $S$ on the four-fold hollow (4fh) sites on $\mathrm{Cu}(100)$ versus the three-fold hollow (3fh) sites on $\mathrm{Cu}(111)$ has been analyzed in detail not just for extended surfaces, but also for nanoclusters (where quantum size effects somewhat disrupt this feature for smaller nanocluster sizes). ${ }^{28}$ The difference in adsorption was attributed to weaker antibonding interactions at the $4 \mathrm{fh}$ site relative the $3 \mathrm{fh}$ site, where we note that bonding interactions with the substrate at $4 \mathrm{fh}$ and 3 fh sites are similar. A recent DFT study of S adsorption on lowindex surfaces considered not just coinage metals, but also $\mathrm{Ni}$, $\mathrm{Pd}, \mathrm{Pt}, \mathrm{Rh}$, and $\mathrm{Ir}^{29}{ }^{29}$ In all cases, adsorption on the (100) surface is stronger than on the (111) surfaces, although the difference is much smaller for Au than all other metals (consistent with the results reported above). Ref. 29 also reports $\mathrm{S}$ diffusion barriers which are far higher on (100) surfaces. The high diffusion barrier on $\mathrm{Ag}(100)$ was previously suggested to impact the limited additiveenhanced mass transport observed on this surface. ${ }^{7}$

Now we take up the challenge of elucidating the difference in behavior on $\mathrm{Ag}(111)$ and $\mathrm{Ag}(100)$ surfaces. For $\mathrm{Ag}_{2} \mathrm{~S}_{3}$, there is little difference between the adsorption energy, $\Delta E_{3}$, of the complex on the (100) and (111) surfaces of Ag. Thus, the source of the difference between the positive formation energy of $\mathrm{Ag}(100)$ and the negative formation energy on $\mathrm{Ag}(111)$ comes almost exclusively from the difference in $\Delta E_{1}$. This difference is in turn exclusively tied to the difference in adsorption energies of $S$ on the $A g(100)$ and $A g(111)$ surfaces. Specifically, the feature that $\mathrm{S}$ adsorbs much more strongly on $\mathrm{Ag}(100)$ as isolated adatoms inhibits the formation of complexes on that surface relative to the $\mathrm{Ag}(111)$ surface. This same interpretation applies to describe the lack of stability of $\mathrm{Ag}_{3} \mathrm{~S}_{3}, \mathrm{Ag}_{3} \mathrm{~S}_{4}$, and $\mathrm{Ag}_{4} \mathrm{~S}_{4}$ on $\mathrm{Ag}(100)$ contrasting their stability on $\mathrm{Ag}(111)$. For $\mathrm{Ag}_{4} \mathrm{~S}_{5}$, adsorption on the $\mathrm{Ag}(111)$ surface is significantly stronger than on $\mathrm{Ag}(100)$, which has the effect of making this complex only weakly unstable on $\mathrm{Ag}(100)$ versus being stable on $\mathrm{Ag}(111)$. (However, since larger complexes such as $\mathrm{Ag}_{16} \mathrm{~S}_{13}$ have even lower chemical potentials than the above smaller complexes on $\mathrm{Ag}(111)$, our LTSTM studies find only the latter and not, e.g., $\mathrm{Ag}_{4} \mathrm{~S}_{5}$ on $\mathrm{Ag}(111)$.)

Similarly for $\mathrm{Cu}_{2} \mathrm{~S}_{3}$, there is little difference between the adsorption energy, $\Delta E_{3}$, on $\mathrm{Cu}(100)$ and $\mathrm{Cu}(111)$. Thus, the source of the difference between the lack of stability on $\mathrm{Cu}(100)$ and the stability on $\mathrm{Cu}(111)$ comes from the difference in $\Delta E_{1}$, which in turn comes from the difference in $E_{\mathrm{ad}}(\mathrm{S})$ on $\mathrm{Cu}(100)$ and $\mathrm{Cu}(111)$ surfaces. Specifically, stronger $\mathrm{S}$ adsorption on $\mathrm{Cu}(100)$ inhibits complex formation relative to $\mathrm{Cu}(111)$.

The picture is quite different for $\mathrm{Au}$. For $\mathrm{AuS}_{2}, \mathrm{Au}_{2} \mathrm{~S}_{3}, \mathrm{Au}_{3} \mathrm{~S}_{4}$, and $\mathrm{Au}_{4} \mathrm{~S}_{5}$, the difference in $\Delta E_{1}$ for $\mathrm{Au}(100)$ and $\mathrm{Au}(111)$ surfaces is relatively small (compared to $\mathrm{Cu}$ and $\mathrm{Ag}$ ) due to the relatively small difference in adsorption energies for $\mathrm{S}$ on these two surfaces. However, the stability of these complexes on $\mathrm{Au}(100)$, but not $\mathrm{Au}(111)$, derives from their stronger adsorption on the $\mathrm{Au}(100)$ surface.

The contrasting behavior for $\mathrm{Ag}$ and $\mathrm{Cu}$ surfaces with that for $\mathrm{Au}$ surfaces is summarized schematically in Fig. 4. This figure
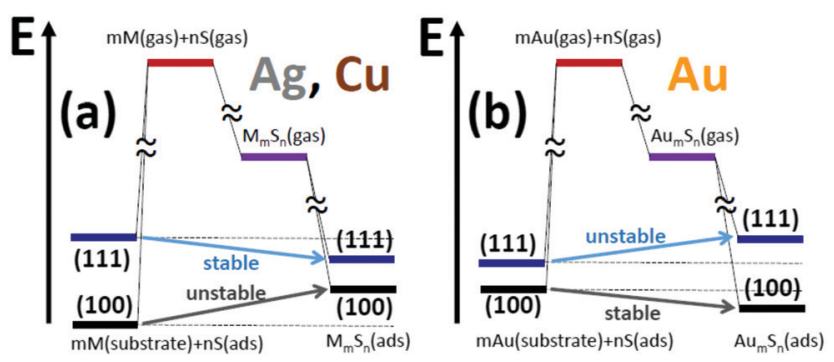

Fig. 4 Schematic of qualitative difference in the energy landscape for formation of adsorbed complexes on (a) Ag \& Cu surfaces versus (b) $\mathrm{Au}$ surfaces. The schematic also elucidates the difference in behavior on (100) and (111) surfaces. 
also illustrates the difference in behavior between (100) and (111) surfaces.

\section{Conclusions}

Our DFT-based analysis of the stability (or otherwise) of M-S complexes on coinage metal $\mathrm{M}=\mathrm{Cu}, \mathrm{Ag}$, and $\mathrm{Au}$ surfaces is entirely consistent with experiment. Stability of complexes is lacking on (100) surfaces of $\mathrm{Cu}$ and $\mathrm{Ag}$, in contrast to the (111) surfaces. Stable complexes are found on $\mathrm{Au}(100)$, but not on $\mathrm{Au}(111)$. The contrasting behavior for (100) versus (111) surfaces, and for $\mathrm{Ag}$ and $\mathrm{Cu}$ versus $\mathrm{Au}$, is effectively elucidated within the framework of Hess's law and shown schematically in Fig. 4. This approach allows an unambiguous decomposition of the various energetic contributions to the stability of complexes. This decomposition demonstrates that a key factor in the lack of stability on (100) surfaces of $\mathrm{Cu}$ and $\mathrm{Ag}$, in contrast to (111) surfaces, is the significantly stronger adsorption of $\mathrm{S}$ adatoms on the (100) surfaces. However, for $\mathrm{Au}$, there is a relatively small difference in adsorption energy for $S$ on (100) versus (111) surfaces. This feature together with stronger adsorption of complexes on the $\mathrm{Au}(100)$ surface produces different behavior than for $\mathrm{Cu}$ and $\mathrm{Ag}$, i.e., complexes are stable on $\mathrm{Au}(100)$ and not on $\mathrm{Au}(111)$.

The lack of stable complexes on $\mathbf{M}(100)$ surfaces for $\mathbf{M}=\mathrm{Ag}$ and $\mathrm{Cu}$ is consistent with observation of only moderately enhanced mass transport of $\mathrm{Ag}(100)$ in the presence of $\mathrm{S}$. We expect that the same will be true for $\mathrm{Cu}(100)$ exposed to $\mathrm{S}$. Again, this contrasts the dramatic enhancement of mass transport on $\mathrm{Ag}(111)$ and $\mathrm{Cu}(111)$ exposed to $\mathrm{S}$. To explain this behavior, we note that for the mass transport pathway associated with a specific mass carrier, the effective activation barrier is given by the sum of the diffusion barrier and the formation energy for the mass carrier (or just the diffusion barrier if the complex formation energy is negative). ${ }^{3,6,8}$ This applies irrespective of whether the carrier is a metal adatom or a complex (although there could be an additional attachment barrier which must be included for the latter). Since the formation energies of metal adatoms are high as indicated in Table 2, even complexes with small positive formation energies (rather than just negative formation energies) can dominate mass transport provided that their diffusion barriers are not too high compared to metal adatoms.

This study also motivates further experimental analysis of mass transport on Au surfaces exposed to S. In particular, such work should assess if significant enhancement occurs on $\mathrm{Au}(100)$ due to stable $\mathrm{Au}_{4} \mathrm{~S}_{5}$ and other complexes. In addition, it is of interest to check if exposure of $\mathrm{Au}(111)$ to just trace amounts of $S$ produces limited enhancement of mass transport, at least compared to the dramatic enhancement seen on $\mathrm{Ag}(111)$ and $\mathrm{Cu}(111)$. It should, however, be noted that strong S-induced surface dynamics has already been observed on $\mathrm{Au}(111)$ for higher surface coverages. ${ }^{30,31}$

\section{Conflicts of interest}

There are no conflicts to declare.

\section{Appendix A: formation energies calculated with alternative methods}

In Table 4, we provide results for formation energies for various $\mathrm{Cu}-\mathrm{S}$ complexes on $\mathrm{Cu}(100)$ obtained at a fixed $\mathrm{S}$ coverage. Analysis for lowest $S$ coverage requires the largest supercells, and thus is particularly computationally demanding. Complexes including more $\mathrm{S}$ atoms also require larger unit cells. In experiment, conversion between $\mathrm{S}$ adatoms and various $\mathrm{M}-\mathrm{S}$ complexes most naturally occurs at a fixed $S$ coverage, corresponding to the analysis presented here. However, as noted in the text, results obtained with fixed supercell size (corresponding to fixed complex coverage) at far lower computational cost are in excellent agreement with the results presented here.

Table 4 Formation energies of $\mathrm{Cu}-\mathrm{S}$ complexes calculated using different approaches. The first three rows are obtained with various supercells adjusted to preserve the same $S$ coverage, which is fixed at $1 / 4,1 / 5$, and $1 / 8 \mathrm{ML}$, respectively. The last row use the same $(4 \times 4)$ supercell for both complexes and $\mathrm{S}$ adatoms

\begin{tabular}{lllllllll} 
Coverage & $\mathrm{CuS}$ & $\mathrm{CuS}_{2}$ & $\mathrm{Cu}_{2} \mathrm{~S}_{2}$ & $\mathrm{Cu}_{2} \mathrm{~S}_{3}$ & $\mathrm{Cu}_{3} \mathrm{~S}_{3}$ & $\mathrm{Cu}_{3} \mathrm{~S}_{4}$ & $\mathrm{Cu}_{4} \mathrm{~S}_{4}$ & $\mathrm{Cu}_{4} \mathrm{~S}_{5}$ \\
\hline 0.250 & 0.76 & 0.57 & 2.26 & 1.34 & 1.82 & 1.30 & 2.03 & 1.29 \\
0.200 & 0.81 & 0.62 & 2.24 & 1.06 & 1.81 & 1.26 & 2.08 & 1.27 \\
0.125 & 0.72 & 0.56 & 2.32 & 1.07 & 1.85 & 1.19 & 2.03 & 1.32 \\
Various & 0.69 & 0.56 & 2.32 & 1.09 & 1.84 & 1.38 & 2.11 & 1.49
\end{tabular}

Table 5 Decomposition of the formation energy (in eV) of metal-sulfur complex on $\mathrm{M}(111)$ surfaces into three elementary steps. Values are missing for $\mathrm{Au}_{2} \mathrm{~S}_{2}$ and $\mathrm{AuS}_{3}$ as these complexes are unstable when adsorbed

\begin{tabular}{|c|c|c|c|c|}
\hline Complex & $\Delta E_{1}$ & $\Delta E_{2}$ & $\Delta E_{3}$ & $E_{\mathrm{f}}(\mathrm{ads})$ \\
\hline CuS & 7.88 & -3.23 & -3.98 & 0.66 \\
\hline $\mathrm{CuS}_{2}$ & 12.23 & -5.82 & -6.31 & 0.10 \\
\hline $\mathrm{Cu}_{2} \mathrm{~S}_{2}$ & 15.70 & -10.02 & -4.74 & 0.94 \\
\hline $\mathrm{CuS}_{3}$ & 16.57 & -7.75 & -8.70 & 0.11 \\
\hline $\mathrm{Cu}_{2} \mathrm{~S}_{3}$ & 20.04 & -11.87 & -8.23 & -0.06 \\
\hline $\mathrm{Cu}_{3} \mathrm{~S}_{3}$ & 23.51 & -16.63 & -6.77 & 0.11 \\
\hline $\mathrm{Cu}_{3} \mathrm{~S}_{4}$ & 27.81 & -17.34 & -10.47 & 0.00 \\
\hline $\mathrm{Cu}_{4} \mathrm{~S}_{4}$ & 31.28 & -23.06 & -7.98 & 0.23 \\
\hline $\mathrm{Cu}_{4} \mathrm{~S}_{5}$ & 35.32 & -22.41 & -12.82 & 0.08 \\
\hline AgS & 6.19 & -2.46 & -3.14 & 0.59 \\
\hline $\mathrm{AgS}_{2}$ & 9.79 & -4.52 & -5.26 & 0.01 \\
\hline $\mathrm{Ag}_{2} \mathrm{~S}_{2}$ & 12.32 & -7.44 & -4.01 & 0.86 \\
\hline $\mathrm{AgS}_{3}$ & 13.38 & -5.78 & -7.47 & 0.13 \\
\hline $\mathrm{Ag}_{2} \mathrm{~S}_{3}$ & 15.90 & -9.06 & -7.03 & -0.19 \\
\hline $\mathrm{Ag}_{3} \mathrm{~S}_{3}$ & 18.43 & -12.69 & -5.85 & -0.12 \\
\hline $\mathrm{Ag}_{3} \mathrm{~S}_{4}$ & 21.98 & -13.32 & -8.96 & -0.31 \\
\hline $\mathrm{Ag}_{4} \mathrm{~S}_{4}$ & 24.50 & -17.49 & -7.33 & -0.32 \\
\hline $\mathrm{Ag}_{4} \mathrm{~S}_{5}$ & 27.81 & -17.34 & -10.94 & -0.47 \\
\hline $\mathrm{AuS}$ & 6.77 & -2.94 & -2.98 & 0.85 \\
\hline $\mathrm{AuS}_{2}$ & 10.30 & -5.92 & -3.92 & 0.46 \\
\hline $\mathrm{Au}_{2} \mathrm{~S}_{2}$ & 13.34 & -8.49 & & \\
\hline $\mathrm{AuS}_{3}$ & 13.79 & -7.51 & & \\
\hline $\mathrm{Au}_{2} \mathrm{~S}_{3}$ & 16.82 & -11.51 & -4.81 & 0.50 \\
\hline $\mathrm{Au}_{3} \mathrm{~S}_{3}$ & 19.86 & -14.92 & -4.65 & 0.29 \\
\hline $\mathrm{Au}_{3} \mathrm{~S}_{4}$ & 23.29 & -16.41 & -6.74 & 0.14 \\
\hline $\mathrm{Au}_{4} \mathrm{~S}_{4}$ & 26.33 & -21.60 & -4.97 & -0.23 \\
\hline $\mathrm{Au}_{4} \mathrm{~S}_{5}$ & 29.57 & -20.87 & -8.26 & 0.44 \\
\hline
\end{tabular}


We should also mention that an alternative method which uses the same supercell $[$ e.g., $(4 \times 4)]$ that is sufficiently large to minimize interactions between complexes, and uses the result of $S$ adsorption at low coverage [e.g., at 1/16 ML using the same $(4 \times 4)$ supercell], can also lead to very reliable estimate of the formation energy. Results using such an approach are included in Table 4. They are mostly the same as the fixed coverage results at $\theta_{\mathrm{S}}=1 / 8 \mathrm{ML}$, except for $\mathrm{Cu}_{3} \mathrm{~S}_{4}$ and $\mathrm{Cu}_{4} \mathrm{~S}_{5}$. This is because these two complexes are less compact than the others, thus a $(4 \times 4)$ supercell is too small to completely ignore interactions between these complexes.

\section{Appendix B: energetics of $\mathrm{M}-\mathrm{S}$ complexes on $M(111)$ surfaces}

We summarize energetics for $\mathbf{M}-\mathrm{S}$ complexes on $\mathbf{M}(111)$ surfaces to facilitate comparison with behavior on $\mathrm{M}(100)$ surfaces. Results for the formation energy, $E_{\mathrm{f}}\left(\mathrm{M}_{m} \mathrm{~S}_{n}\right)$ (ads), of adsorbed complexes are decomposed within the framework of Hess's law into energies associated with three steps: (1) desorption of atoms from the surface; (2) formation of the complex in the gas phase; and (3) adsorption of the complex onto the surface. Results are presented in Table 5 in a format entirely analogous to the presentation for $\mathrm{M}(100)$ surfaces in Table 3 . These data were published previously in ref. 18.

\section{Acknowledgements}

D.-J. L., J. L., T. L. W., and J. W. E. performed the theoretical analysis and computations in this work, and were supported by the U.S. Department of Energy (USDOE), Office of Basic Energy Sciences, Division of Chemical Sciences, Geosciences, and Biosciences through the Ames Laboratory Chemical Physics program. We acknowledge use of resources of the National Energy Research Scientific Computing Center, a DOE Office of Science User Facility supported by the Office of Science of the U.S. DOE under Contract No. DE-AC02-05CH11231. P. M. S. performed the S/Ag(100) LTSTM experiment under the supervision P. A. T. who also contributed to the formulation of this project, and they were supported for this work by NSF Grant No. CHE-1507223. The work was performed at Ames Laboratory which is operated for the USDOE by Iowa State University under Contract No. DE-AC02-07CH11358.

\section{Notes and references}

1 P. J. F. Harris, Int. Mater. Rev., 1995, 40, 97-115.

2 W. L. Ling, N. C. Bartelt, K. Pohl, J. de la Figuera, R. Q. Hwang and K. F. McCarty, Phys. Rev. Lett., 2004, 93, 166101.

3 P. A. Thiel, M. Shen, D.-J. Liu and J. W. Evans, J. Vac. Sci. Technol., A, 2010, 28, 1285.

4 K. F. Kalz, R. Kraehnert, M. Dvoyashkin, R. Dittmeyer, R. Gläser, U. Krewer, K. Reuter and J.-D. Grunwaldt, ChemCatChem, 2017, 9, 17-29.
5 https://science.energy.gov//media/bes/pdf/reports/2017/ BRNCatalysisScience_rpt.pdf, Basic Research Needs for Catalysis Science to Transform Energy Technologies, USDOE BES Workshop, Gaithersburg, Maryland.

6 M. Shen, D.-J. Liu, C. J. Jenks, P. A. Thiel and J. W. Evans, J. Chem. Phys., 2009, 130, 094701.

7 M. Shen, S. M. Russell, D.-J. Liu and P. A. Thiel, J. Chem. Phys., 2011, 135, 154701.

8 P. J. Feibelman, Phys. Rev. Lett., 2000, 85, 606.

9 A. R. Layson, J. W. Evans and P. A. Thiel, Phys. Rev. B: Condens. Matter Mater. Phys., 2002, 65, 193409.

10 P. Wynblatt and N. A. Gjostein, Acta Metall., 1976, 24, 1165.

11 N. Philipp and F. Abild-Pedersen, ACS Catal., 2016, 6, 7098-7108.

12 H. Walen, D.-J. Liu, J. Oh, H. Lim, J. W. Evans, C. M. Aikens, Y. Kim and P. A. Thiel, Phys. Rev. B: Condens. Matter Mater. Phys., 2015, 91, 045426.

13 H. Walen, D.-J. Liu, J. Oh, H. Lim, J. W. Evans, Y. Kim and P. A. Thiel, J. Chem. Phys., 2015, 142, 194711.

14 H. Walen, D.-J. Liu, J. Oh, H. J. Yang, P. M. Spurgeon, Y. Kim and P. A. Thiel, J. Phys. Chem. B, 2018, 122, 963-971.

15 S. M. Russell, Y. Kim, D.-J. Liu, J. W. Evans and P. A. Thiel, J. Chem. Phys., 2013, 138, 071101.

16 H. Walen, D.-J. Liu, J. Oh, H. Lim, J. W. Evans, Y. Kim and P. A. Thiel, J. Chem. Phys., 2015, 143, 014704.

17 H. Walen, D.-J. Liu, J. Oh, H. J. Yang, Y. Kim and P. A. Thiel, Phys. Chem. Chem. Phys., 2016, 18, 4891.

18 J. Lee, T. L. Windus, P. A. Thiel, J. W. Evans and D.-J. Liu, J. Phys. Chem. C, 2019, 123, 12954.

19 G. Kresse and J. Hafner, Phys. Rev. B: Condens. Matter Mater. Phys., 1993, 47, R558-R561.

20 G. Kresse and J. Hafner, Phys. Rev. B: Condens. Matter Mater. Phys., 1994, 49, 14251.

21 P. E. Blöchl, Phys. Rev. B: Condens. Matter Mater. Phys., 1994, 50, 17953-17979.

22 G. Kresse and D. Joubert, Phys. Rev. B: Condens. Matter Mater. Phys., 1999, 59, 1758-1775.

23 J. P. Perdew, K. Burke and M. Ernzerhof, Phys. Rev. Lett., 1996, 77, 3865-3868.

24 P. M. Spurgeon, D.-J. Liu, H. Walen, J. Oh, H. J. Yang, Y. Kim and P. A. Thiel, Phys. Chem. Chem. Phys., 2019, 21, 10540-10551.

25 D.-J. Liu, J. Lee, T. L. Windus, P. A. Thiel and J. W. Evans, Surf. Sci., 2018, 676, 2-8.

26 D.-J. Liu, Phys. Rev. B: Condens. Matter Mater. Phys., 2010, 81, 035415.

27 M. K. Bradley, D. P. Woodruff and J. Robinson, Surf. Sci., 2013, 613, 21-27.

28 J. S. Boschen, J. Lee, T. L. Windus, J. W. Evans, P. A. Thiel and D.-J. Liu., J. Chem. Phys., 2016, 145, 164312.

29 C. R. Bernard Rodríguez and J. A. Santana, J. Chem. Phys., 2018, 149, 204701.

30 M. M. Biener, J. Biener and C. M. Friend, Langmuir, 2005, 21, 1668.

31 M. M. Biener, J. Biener and C. M. Friend, Surf. Sci., 2007, 601, 1659-1667. 